\title{
Recurrent mutation in the crystallin alpha A gene associated with inherited paediatric cataract
}

\author{
Shari Javadiyan ${ }^{*}$, Jamie E. Craig ${ }^{1}$, Emmanuelle Souzeau' ${ }^{1}$ Shiwani Sharma ${ }^{1}$, Karen M. Lower ${ }^{2}$, John Pater ${ }^{3}$, \\ Theresa Casey ${ }^{3}$, Trevor Hodson ${ }^{4}$ and Kathryn P. Burdon ${ }^{1,5}$
}

\begin{abstract}
Background: Cataract is a major cause of childhood blindness worldwide. The purpose of this study was to determine the genetic cause of paediatric cataract in a South Australian family with a bilateral lamellar paediatric cataract displaying variable phenotypes.

Case presentation: Fifty-one genes implicated in congenital cataract in human or mouse were sequenced in an affected individual from an Australian (Caucasian) family using a custom Ampliseq library on the lon Torrent Personal Genome Machine. Reads were mapped against the human genome (hg19) and variants called with the Torrent Suite software. Variants were annotated to dbSNP 137 using lon Reporter (IR 1.6.2) and were prioritised for validation if they were novel or rare and were predicted to be protein changing. We identified a previously reported oligomerization disrupting mutation, c.62G > A (p.R21Q), in the Crystallin alpha A (CRYAA) gene segregating in this three generation family. No other novel or rare coding mutations were detected in the known cataract genes sequenced. Microsatellite markers were used to compare the haplotypes between the family reported here and a previously published family with the same segregating mutation. Haplotype analysis indicated a potential common ancestry between the two South Australian families with this mutation. The work strengthens the genotype-phenotype correlations between this functional mutation in the crystallin alpha A (CRYAA) gene and paediatric cataract.
\end{abstract}

Conclusion: The p.R21Q mutation is the most likely cause of paediatric cataract in this family. The recurrence of this mutation in paediatric cataract families is likely due to a familial relationship.

Keywords: CRYAA, Congenital cataract, Paediatric cataract, lon Ampliseq technologies, Next generation sequencing, PGM

\section{Background}

Congenital or paediatric cataract is one of the major causes of lifelong visual loss in children [1] and 8-25\% of congenital cataract are inherited [2]. Inherited cataracts can be transmitted as autosomal recessive, autosomal dominant or X-linked traits, although autosomal dominant is the most common mode of inheritance. Both genetic and clinical heterogeneity have been observed

\footnotetext{
*Correspondence: shahra_80@yahoo.com

${ }^{1}$ Department of Ophthalmology, School of Medicine, Flinders Medical Centre, Flinders University, Rm 4D 111.1, Flinders Dr, Bedford Park, Adelaide 5042, Australia

Full list of author information is available at the end of the article
}

and congenital cataract can occur in isolation or be associated with other systemic features as part of a metabolic or genetic syndrome [3].

Isolated inherited congenital cataracts have thus far been found to be associated with mutations in genes that encode structural proteins (including the crystallins), membrane proteins, transcription factors, signalling molecules and enzymes [4]. Crystallin genes are the largest known gene family linked with congenital cataract; mutations in several members of this gene family are known to cause the disease. More than 60 different mutations in crystallin genes have been reported to date in patients 
with paediatric cataracts and these mutations are associated with a range of cataract phenotypes $[5,6]$.

Here we aimed to determine the genetic cause of paediatric cataract in a multi-generation South Australian family using a high throughput screen of known cataract genes. We report a second occurrence of the p.R21Q mutation in the CRYAA gene and investigated the ancestral origins of the mutation between the two families with paediatric cataract.

\section{Case presentation}

Six members of the three generation Australian (Caucasian) family CSA110 (Fig. 1) were diagnosed with pediatric cataract. The proband CSA110.01 presented with bilateral lamellar cataracts diagnosed at 7 years of age and had bilateral cataract surgery at age 16. Her mother, CSA110.03 also had bilateral cataracts which were diagnosed at 12 years of age and had bilateral cataract surgery at the age of 46 . CSA110.07, the proband's maternal uncle, had severe bilateral cataracts which were surgically removed at age 4 years. The proband's grandmother, CSA110.04 had bilateral cataract surgery at the age of 76 but no information was available on the cataract phenotype. Her brother, CSA110.05, had bilateral mild lamellar cataracts, with anterior cortical spokes (Fig. 2) and had cataract surgery at age 61 . These siblings had surgery significantly later than their children and grandchildren; the cataract of CSA110.05 was described as lamellar affecting the fetal nucleus indicating its congenital nature despite the late surgical intervention. The proband's brother, CSA110.02 shows no evidence of cataracts at the last examination in 2005 when he was 20 years old.

\section{Discussion}

Due to the heterogeneity of congenital cataract, an approach was taken that allows screening of multiple genes simultaneously. DNA (Deoxyribonucleic acid) was extracted from whole blood from all participants using

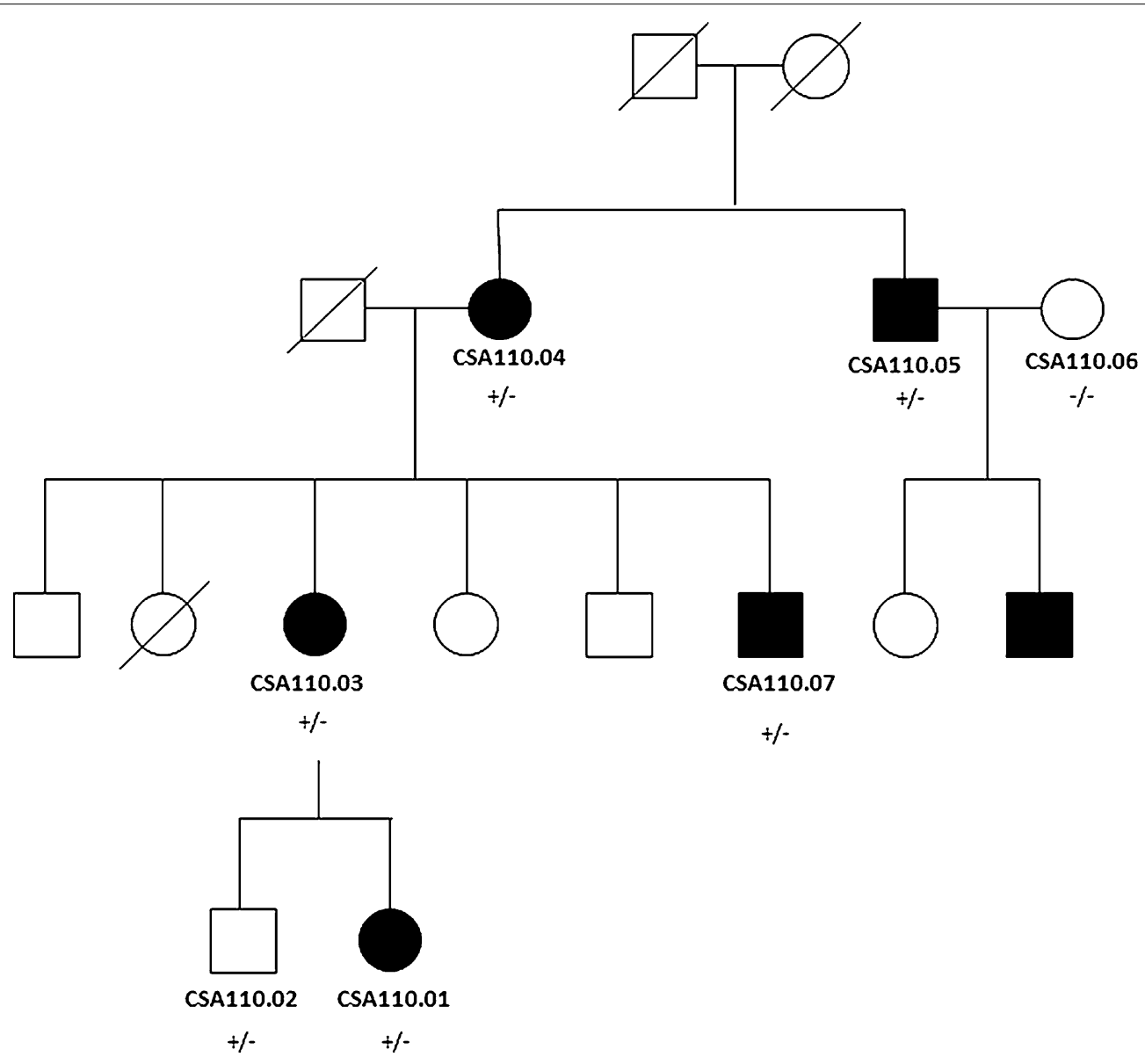

Fig. 1 Pedigree of family CSA110 with mutation in CRYAA. Individuals with ID numbers were examined by an ophthalmologist. Solid circles indicate affected females and solid squares indicate affected males. Plus sign indicates mutant allele and minus sign indicates wild type allele. Diagonal lines indicate the individual is deceased 

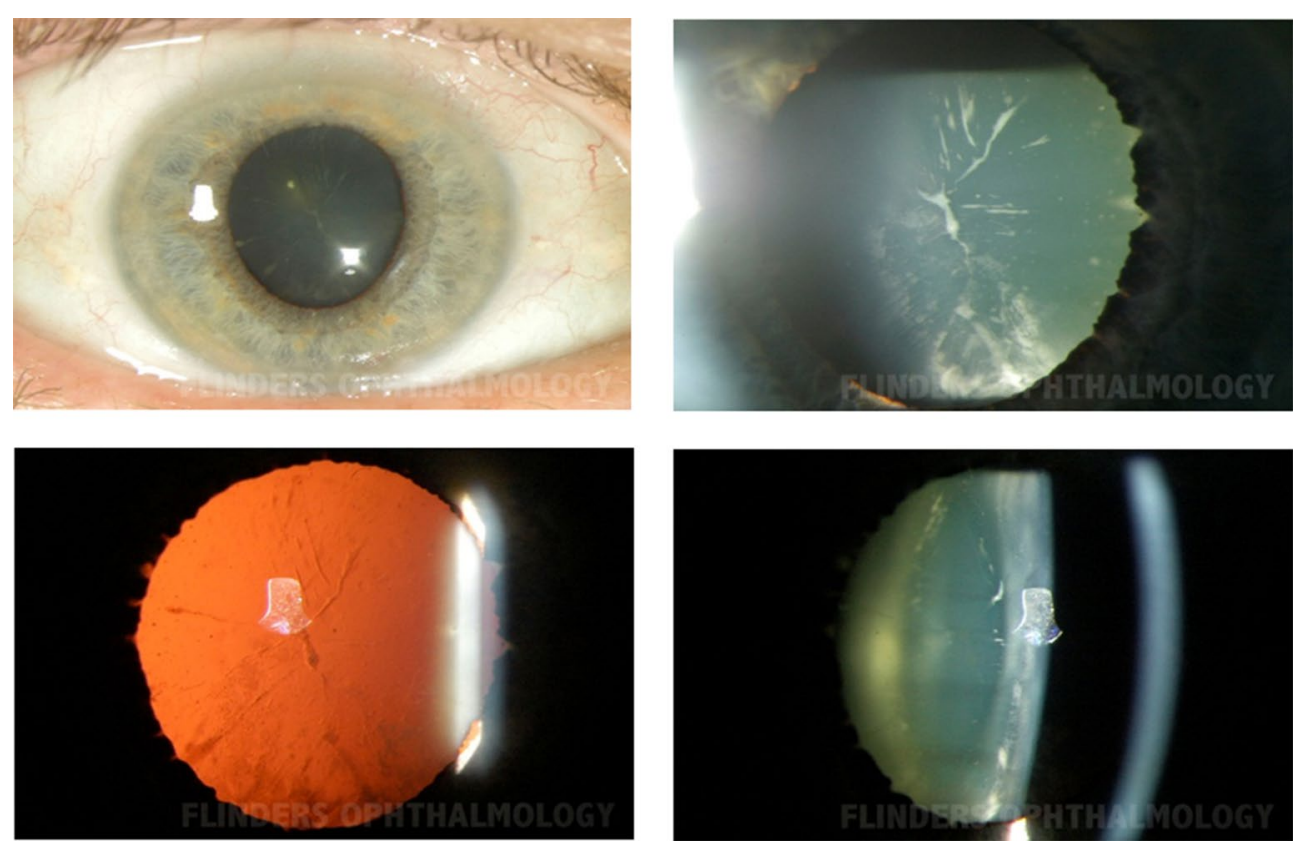

Fig. 2 Phenotype of cataract in CSA1 10.05 showing lamellar and cortical cataract with white spokes

the QIAamp DNA blood maxi kit (Qiagen, Hilden, Germany) according to the manufacturer's protocol. Fiftyone genes known to cause congenital cataract in human or mouse were selected through a review of the literature and are listed in Additional file 1 [4, 7-18]. We included all the genes listed in a recent review of congenital cataract genes [4] except gifl which does not appear to have a human analogue. Additional genes from more recent publications or not included in the aforementioned review were also included (Additional file 1).

PCR (polymerase chain reaction) primers to amplify coding and untranslated regions of the 51 genes were designed with the Ion Ampliseq Designer (Life Technologies, www.ampliseq.com). A total of 1216 amplicons ranging from $125 \mathrm{bp}$ to $225 \mathrm{bp}$ covered $94.26 \%$ of the target sequence. Primers were supplied in two pools, $100 \mathrm{nM}$ concentration each (Life Technologies, Carlsbad, CA, USA). The sequencing library was prepared with the Ion AmpliSeq library kit version 2.0 according to the manufacturer's protocols for affected individual CSA110.03. The amplified library was diluted to $10 \mathrm{pM}$ and $25 \mu \mathrm{L}$ was used for template preparation according to Ion PGM Template OT2 200 Kit protocol using Ion PGM Template OT2 200 Kit. The clonally amplified library then was enriched on Ion OneTouch ES.

Sequencing was performed on an Ion Torrent Personal Genome Machine using The Ion PGM Sequencing 200 Kit v2 and an Ion 318 chip. Using Torrent Suite (version 3.6.) and related plugins for coverage analysis and variant calling, 1197237 reads were mapped against the reference genome (hg19), of which $93.30 \%$ were on target. An average read depth of 918.6 was calculated for total of 1216 amplicons and $94.3 \%$ of the target bases were covered at least $100 \times$. Variant call format (VCF) files were uploaded to Ion Reporter V4.0 (https://ionreporter.lifetechnologies.com/ir/) for variant annotation. Variants were prioritized for further analysis if they were predicted to alter protein sequence, and were absent in dbSNP137, Exome Variant Server (EVS) (http://evs.gs.washington.edu/ $\mathrm{EVS} /$ ) and in an in-house list of sequencing errors previously seen on this gene panel. The variant is present in Exome Aggregation Consortium (ExAC) with a minor allele frequency of 0.000016 .

A total of 121 variants were annotated against dbSNP137, of which 1 was predicted to alter protein sequence. Interestingly, the detected mutation (c.62G > A, p.R21Q) in CRYAA (NM_0003941, MIM\#123580) was previously shown to be a oligomerization disrupting mutation in another South Australian family independently recruited to our congenital cataract research program (Family CSA91) [19]. All the affected family members as well as one unaffected member (CSA110.02) carried the mutation as determined by Sanger sequencing (Fig. 3) using primers and methods described previously [19].

Haplotype analysis was performed in the family previously reported to carry the same missense mutation (CSA91) [19] and the new family reported here 

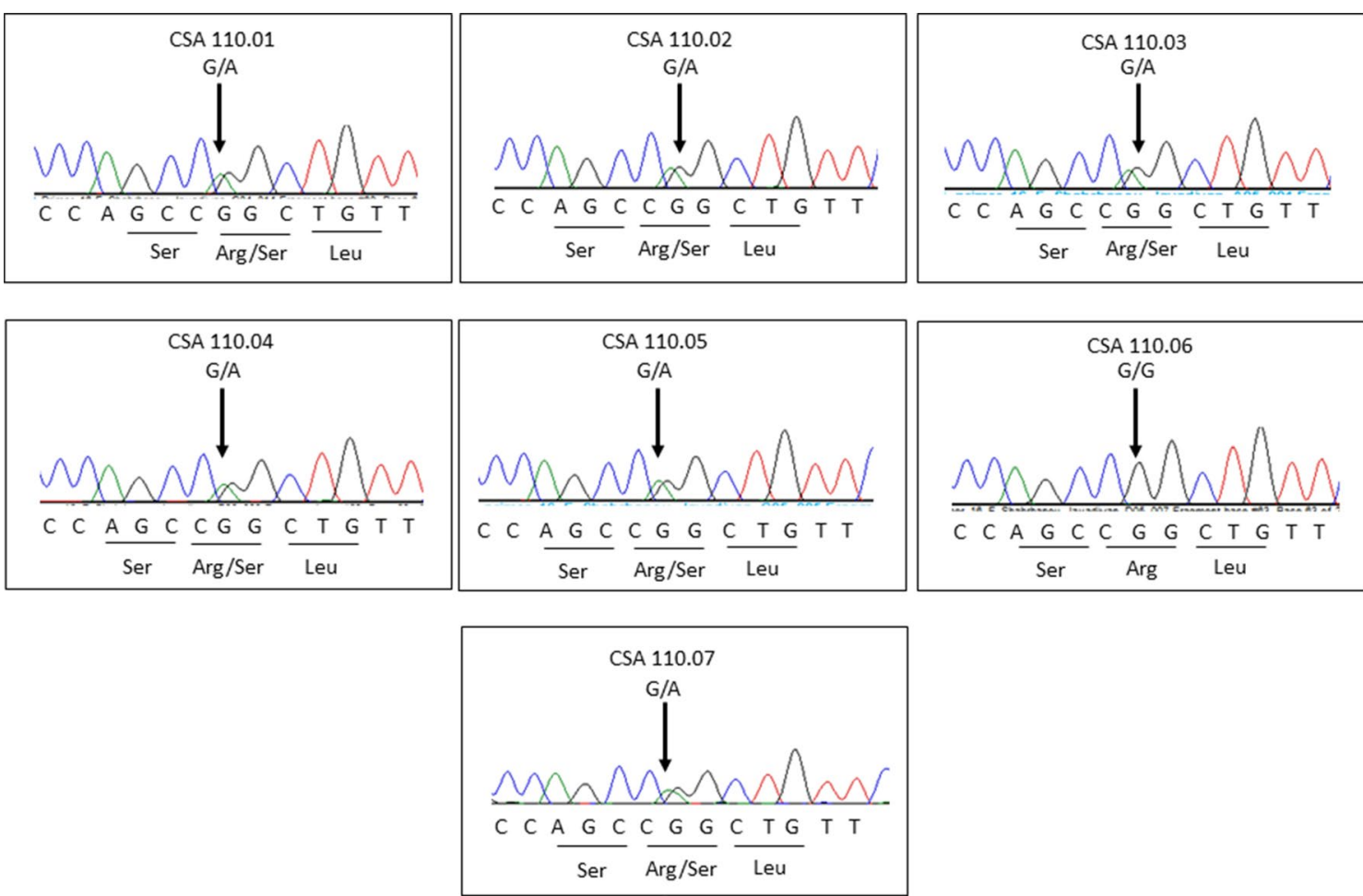

Fig. 3 Sequence chromatogram of all examined individuals at the c.62G > A mutation. All affected family members are heterozygous, as is an unaffected individual CSA110.02

(CSA110) to determine if the mutation has arisen in both families independently, or if they are distantly related. Three microsatellite markers (D21S1260, D21S1890 and D21S1912) on the $\mathrm{q}$ arm of chromosome 21 flanking the CRYAA gene were typed in all available members of the two families. Primer sequences for amplification of each marker are provided in Additional file 2. Forward primers were labelled on the $5^{\prime}$ end with fluorescent dye FAM or HEX. PCR reactions of $20 \mu \mathrm{l}$ final volume consisting of $1 \times$ Coraload PCR buffer (Qiagen) which gave a final concentration of $1.5 \mathrm{mM} \mathrm{Mg}{ }^{2+}, 0.1 \mathrm{mM}$ dNTPs (Roche Diagnostics), $0.5 \mu \mathrm{M}$ each primer, $0.5 \mathrm{U}$ Hot Star Plus Taq Polymerase (Qiagen) and 80 ng of DNA ( $5 \times$ Q solution) (Qiagen) was included at a final concentration of $1 \times$ for markers D21S1890 and D21S1912. PCR was performed on a Palm cycler (Corbett Life science, QIAGEN) with 1 cycle of $95^{\circ} \mathrm{C}$ for $5 \mathrm{~min}$, followed by 35 cycles of $95^{\circ} \mathrm{C}$ for $30 \mathrm{~s}, 57^{\circ} \mathrm{C}$ for $30 \mathrm{~s}, 72{ }^{\circ} \mathrm{C}$ for $30 \mathrm{~s}$ and a final extension step of $72^{\circ} \mathrm{C}$ for $15 \mathrm{~min}$. PCR products were each diluted 1:15. Fragment analysis was carried out on a $3130 \mathrm{xl}$ Genetic Analyser (Life Technologies, NY USA) using GS500LIZ_3130 size standard at the Flinders Sequencing Facility (Flinders Medical Centre, Adelaide, South Australia). Fragment sizes were determined by comparing to the size standard using Peak Scanner Software Version
1 (Life Technologies). Haplotypes were reconstructed using Merlin [20]. A recombination event was detected in CSA91.05 between CRYAA and D21S2160.

All of the mutation carriers in family CSA 110 share a haplotype across this region of chromosome 21 with the affected family members of CSA91, indicating that the mutation has likely arisen only once on this genetic background (Fig. 4). The haplotype carrying the mutant allele was identical in the two families, suggesting that the recurrence of the mutation was possibly due to a previously unrecognised familial relationship (Fig. 4a, b).

\section{Conclusion}

$\propto$ A-crystallin is expressed preferentially in the lens and is detectable during the early stages of lens development. It is present in high concentrations and is responsible for maintaining the transparency of the lens through chaperone like activities and by interacting with damaged or incorrectly folded proteins to prevent their precipitation [21]. It is expressed in the lens epithelium at low levels, and in the elongation zone at higher levels [22], and plays a role in the differentiation of lens epithelial cells to lens fibre cells.

Performing high throughput sequencing of 51 congenital cataract causing genes identified only one potential 


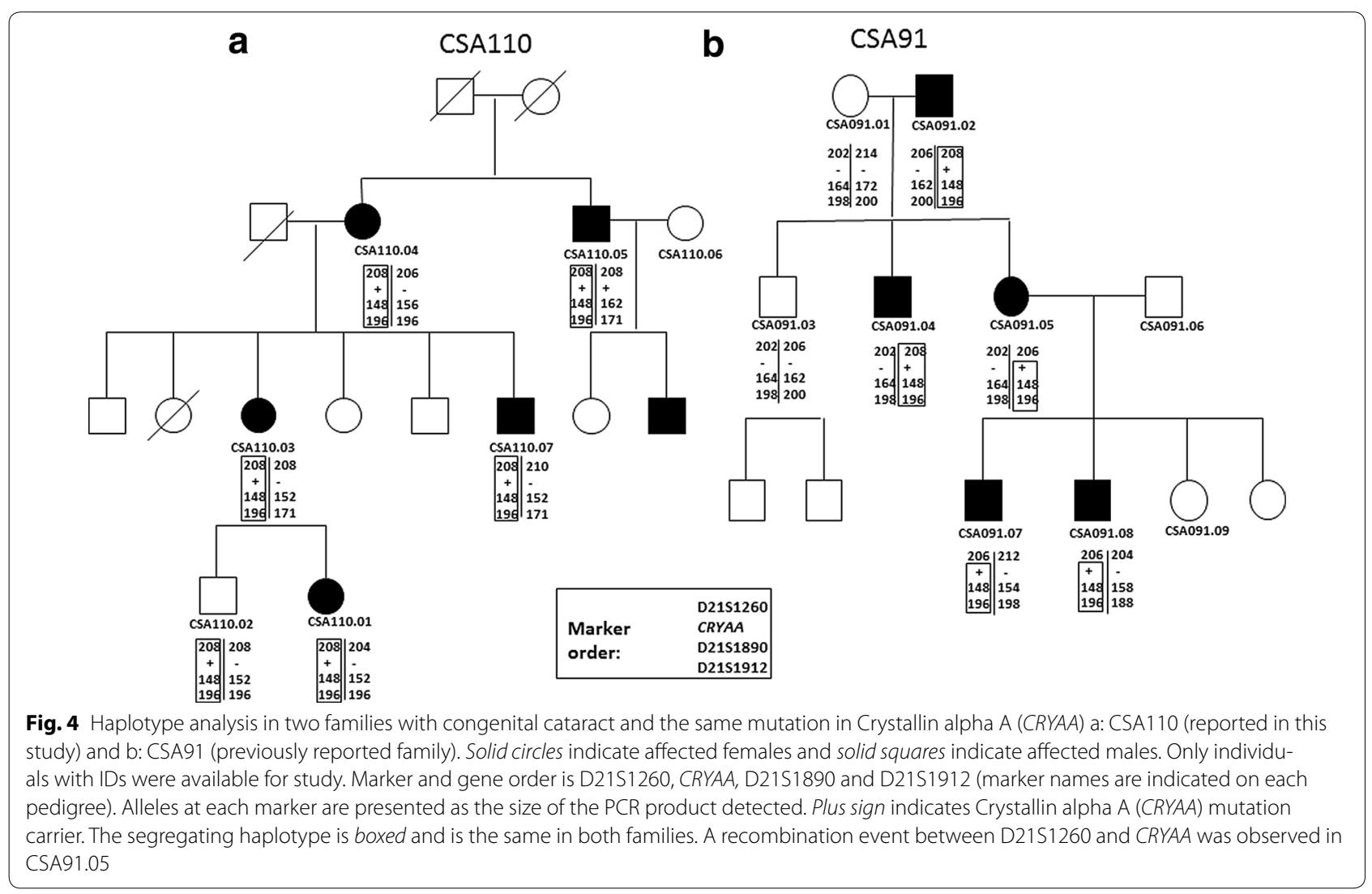

disease causing mutation in family CSA110. This mutation is located in CRYAA and segregated with the phenotype in the family. Of seven available family members, all five affected members carried the mutation, whilst one of the unaffected members also carried the mutation indicating probable reduced penetrance. Previously, the same oligomerization disrupting mutation in CRYAA, c.62G > A (p.R21Q), was reported in an apparently unrelated Australian family with lamellar congenital cataract of variable severity [19]. The detection of the same mutation in CRYAA in two families from the same state of Australia and with such a similar phenotype led us to question whether these families were related. Genetic analysis suggests that the mutation has arisen only once on the same haplotype, and therefore these families are likely to be distantly related. No genealogical link was readily identified on specific questioning. The mutation was not detected previously in Australian controls, nor was it present in commonly accessed databases at the time of sequencing, however, it has subsequently been reported in the ExAC database (http://exac.broadinstitute.org/) with a minor allele frequency of 0.000016 (i.e. 1.6/100,000 chromosomes). Thus, this variant is extremely rare, which is consistent with a role in a rare disease such as pediatric cataract.
Limitations of this study (and any amplicon based next generation sequencing platform) include missing coverage of target genes due to both limitations in oligo design and poor amplification of some amplicons. However, the CRYAA mutation is the most probable cause of the observed phenotype in this family as demonstrated by segregation in two families, and its reported functional effects [19]. Despite the proven advantages of exome sequencing platforms for genetic diagnosis in Mendelian and complex diseases, including congenital cataract [2325], we decided to use a targeted sequencing approach due to its lower cost (at the time of conducting current research) and the simplified analytical pipeline for targeted re-sequencing. The findings from this study would be equally applicable to performing subset analysis of exome or genome sequencing data.

The phenotype in the previously reported family CSA91 is described as lamellar with variable severity [19] which is similar to the observed phenotype in CSA110 with variability in both severity and age at diagnosis. The inheritance pattern in CSA110 is autosomal dominant, but the mutation is not fully penetrant, in agreement with the earlier report of this mutation [13]. Since the p.R21Q CRYAA mutation displays both intra- and inter-familial variability, we postulate the presence of modifier genes 
altering the penetrance of the mutation and the severity of the cataract. There have been previous suggestions of modifier genes involved in the development of congenital cataract [26-28], although such genes have not yet been identified. Of note, mutations in GJA3 and CRYBB2 have been reported with reduced penetrance in congenital and pediatric cataract in humans and a digenic cause of cataract has been reported in a mouse model [28].

A phenotype of lamellar cataract with variable severity is starting to emerge in the literature for CRYAA mutations. To date, 11 mutations in CRYAA have been detected in congenital cataract patients with a variety of cataract phenotypes including lamellar cataract (Table 1). For example, Zhang et al., 2009, described a three-generation Chinese family with autosomal dominant cataract with a mutation in CRYAA (p.R12C). The proband was diagnosed with bilateral lamellar cataract at 1 year of age while his father has milder lamellar cataract diagnosed at 45 years of age. Other family members were diagnosed with older ages of onset of cataracts. The phenotype in this Chinese family is similar in both appearance and severity to our two Australian families.

There have been several CRYAA mutations reported in multiple families, although the ancestral origins have not been assessed for most. Hansen et al. [29], investigated the founder effect of a recurrent mutation (c.61C $>\mathrm{T}$, p.R21 W) in 3 families using the SNP rs 872331 located 55 nucleotides upstream of the mutant codon. They detected an identical haplotype c. [6T; 61C] in two of the families which confirmed their common ancestral founder with subsequent genealogical studies. The detection of the $\mathrm{c}$. $[6 \mathrm{C} ; 61 \mathrm{C}]$ haplotype in the third family suggested that the mutation arose independently in that family.

The observed mutation in family CSA 110 and CSA91 alters a highly conserved arginine residue at position 21 to glutamine (Fig. 5). It lies within the $\mathrm{N}$ terminal domain of CRYAA which has been demonstrated to be important for subunit exchange and oligomerization. It has been suggested that the deletion of this highly conserved amino acid which is located in a conserved motif (SRLFDQFFG), leads to disruption of the correct assembly of quaternary alpha-crystallin structure [30]. Western blotting of lens protein from a mutation carrier also showed a decrease in the ability of the protein to form higher order oligomers essential for its function [19]. There have been multiple reports of mutations altering the highly conserved arginine residue at position 21 (p.R21 W and p.R21L) associated with a variety of congenital cataract phenotypes, indicating its importance for proper CRYAA function.

In conclusion, we have identified a second instance of the p.R21Q mutation in the CRYAA gene in a family with congenital cataract and demonstrated the likelihood of these two families being distantly related. Both families showed similar phenotypes of lamellar cataracts with variable age of onset and severity, demonstrating intraand inter-familial variability and incomplete penetrance associated with this mutation. This study highlights the local founder effects that may be seen within a community and further strengthens the genotype-phenotype correlations reported for the CRYAA gene with congenital cataract.

\section{Consent}

The study adhered to the tenets of the Declaration of Helsinki and was approved by the Southern Adelaide Clinical Human Research Ethics Committee. The proband of family CSA110 (individual 110.01) was identified on presentation to the eye clinic at Flinders Medical Centre (FMC), Adelaide, South Australia. Written informed consent was obtained from all of the family members and/ or their guardians for publication of this Case Report and any accompanying images. A copy of the written consent is available for review by the Editor-in-Chief of

Table 1 Mutations in crystallin alpha A (CRYAA) gene associated with pediatric or congenital cataract

\begin{tabular}{llllll}
\hline Exon & DNA change & Protein change & Mode of inheritance & Reported phenotypes & References \\
\hline 1 & C.34C $>$ T & p.R12C & AD & Congenital, nuclear, lamellar & {$[25,31-34]$} \\
1 & c.61C $>$ T & p.R21 W & AD & Congenital, laminar nuclear, polar, anterior polar & {$[24,29,31,35]$} \\
1 & c.62G $>$ A & p.R21Q & AD & Lamellar & {$[19]$} \\
1 & c.62G $>$ T & p.R21L & Sporadic & Central posterior & {$[36]$} \\
1 & c.145C $>$ T & p.R49C & AD & Central nuclear & {$[29,37]$} \\
1 & c.160C $>$ T & p.R54C & AR & Total, nuclear & {$[31,38]$} \\
1 & c.161G $>$ C & p.R54P & AD & Y-sutural & {$[39]$} \\
1 & c.161G $>$ T & p.R54L & AD & Nuclear & {$[40]$} \\
2 & c.292G $>$ A & p.G98R & AD & Lamellar, punctate, Y-suture & {$[41,42]$} \\
3 & c.346C $>$ T & p.R116C & AD & Zonular central nuclear, nuclear & {$[41,43,44]$} \\
3 & c.347G $>$ A & p.R116H & AD & Variable, nuclear, punctate, total & {$[35,45-47]$} \\
\hline
\end{tabular}




Human
Mutated (Human)
P. troglodytes
F. catus
M. musculus
G. gallus
T. rubripes
D. rerio
X.tropicalis

$\begin{array}{llllllllllllllllllllll}\mathbf{F} & \mathbf{K} & \mathbf{R} & \mathbf{T} & \mathbf{L} & \mathbf{G} & \mathbf{P} & \mathbf{F} & \mathbf{Y} & \mathbf{P} & \mathbf{S} & \mathbf{R} & \mathbf{L} & \mathbf{F} & \mathbf{D} & \mathbf{Q} & \mathbf{F} & \mathbf{F} & \mathbf{G} & \mathbf{E} & \mathbf{G} \\ \mathbf{F} & \mathbf{K} & \mathbf{R} & \mathbf{T} & \mathbf{L} & \mathbf{G} & \mathbf{P} & \mathbf{F} & \mathbf{Y} & \mathbf{P} & \mathbf{S} & \mathbf{Q} & \mathbf{L} & \mathbf{F} & \mathbf{D} & \mathbf{Q} & \mathbf{F} & \mathbf{F} & \mathbf{G} & \mathbf{E} & \mathbf{G} \\ \mathbf{F} & \mathbf{K} & \mathbf{R} & \mathbf{T} & \mathbf{L} & \mathbf{G} & \mathbf{P} & \mathbf{F} & \mathbf{Y} & \mathbf{P} & \mathbf{S} & \mathbf{R} & \mathbf{L} & \mathbf{F} & \mathbf{D} & \mathbf{Q} & \mathbf{F} & \mathbf{F} & \mathbf{G} & \mathbf{E} & \mathbf{G} \\ \mathbf{F} & \mathbf{K} & \mathbf{R} & \mathbf{A} & \mathbf{L} & \mathbf{G} & \mathbf{P} & \mathbf{F} & \mathbf{Y} & \mathbf{P} & \mathbf{S} & \mathbf{R} & \mathbf{L} & \mathbf{F} & \mathbf{D} & \mathbf{Q} & \mathbf{F} & \mathbf{F} & \mathbf{G} & \mathbf{E} & \mathbf{G} \\ \mathbf{F} & \mathbf{K} & \mathbf{R} & \mathbf{A} & \mathbf{L} & \mathbf{G} & \mathbf{P} & \mathbf{F} & \mathbf{Y} & \mathbf{P} & \mathbf{S} & \mathbf{R} & \mathbf{L} & \mathbf{F} & \mathbf{D} & \mathbf{Q} & \mathbf{F} & \mathbf{F} & \mathbf{G} & \mathbf{E} & \mathbf{G} \\ \mathbf{F} & \mathbf{K} & \mathbf{R} & \mathbf{A} & \mathbf{L} & \mathbf{G} & \mathbf{P} & \mathbf{L} & \mathbf{I} & \mathbf{P} & \mathbf{S} & \mathbf{R} & \mathbf{L} & \mathbf{F} & \mathbf{D} & \mathbf{Q} & \mathbf{F} & \mathbf{F} & \mathbf{G} & \mathbf{E} & \mathbf{G} \\ \mathbf{F} & \mathbf{R} & \mathbf{R} & \mathbf{A} & \mathbf{L} & \mathbf{G} & \mathbf{S} & \mathbf{A} & \mathbf{Y} & \mathbf{P} & \mathbf{T} & \mathbf{R} & \mathbf{L} & \mathbf{F} & \mathbf{D} & \mathbf{Q} & \mathbf{F} & \mathbf{F} & \mathbf{G} & \mathbf{E} & \mathbf{G} \\ \mathbf{F} & \mathbf{R} & \mathbf{R} & \mathbf{T} & \mathbf{L} & \mathbf{G} & - & - & \mathbf{Y} & \mathbf{P} & \mathbf{T} & \mathbf{R} & \mathbf{L} & \mathbf{F} & \mathbf{D} & \mathbf{Q} & \mathbf{F} & \mathbf{F} & \mathbf{G} & \mathbf{E} & \mathbf{G} \\ \mathbf{F} & \mathbf{K} & \mathbf{R} & \mathbf{S} & \mathbf{L} & \mathbf{G} & \mathbf{P} & \mathbf{L} & \mathbf{Y} & \mathbf{P} & \mathbf{N} & \mathbf{R} & \mathbf{L} & \mathbf{F} & \mathbf{D} & \mathbf{Q} & \mathbf{V} & \mathbf{F} & \mathbf{G} & \mathbf{E} & \mathbf{G}\end{array}$

Fig. $\mathbf{5}$ Protein sequence alignments demonstrating the conservation of the altered amino acid (underlined). The figure shows the alignments of crystallin alpha A protein sequence of the region of interest from seven species to the human crystallin alpha A (CRYAA) protein. Both mutated and normal human protein sequences are shown beside sequences from Pan troglodytes (chimpanzee), Felis catus (cat), Mus musculus (mouse), Gallus gallus (rooster), Takifugu rubripes (fish), Danio rerio (zebrafish) and Xenopus tropicalis (Frog)

this journal. Where participants were minor (under the age of 18) or unable to personally provide consent, written informed consent was obtained from the parent or legal guardian. A detailed family history was obtained, and additional affected and unaffected family members invited to participate.

\section{Additional files}

Additional file 1: A table that lists reported pediatric cataract genes selected for sequencing in this study.

Additional file 2. List of Primer sequences for the three microsatellite markers used for haplotype analysis, their position on chromosome 21 (centiMorgan) and their genomic location.

\section{Abbreviations}

CRYAA: crystallin alpha A; PCR: polymerase chain reaction; ExAC: exome aggregation consortium; PGM: personal genome machine.

\begin{abstract}
Authors' contributions
SJ, JEC, SS, ES, KML, and KPB contributed to the conception, design and interpretation of data. SJ carried out the molecular genetic studies, data analysis, and was in charge of manuscript preparation. KPB has been involved in drafting the manuscript critically. JEC, SS, ES and KML also helped with the manuscript preparation. JEC, JP, TC and TH helped with patient recruitment and clinical information. All authors read and approved the final manuscript.
\end{abstract}

\section{Author details}

1 Department of Ophthalmology, School of Medicine, Flinders Medical Centre, Flinders University, Rm 4D 111.1, Flinders Dr, Bedford Park, Adelaide 5042, Australia. ${ }^{2}$ Department of Haematology and Genetic Pathology, School of Medicine, Flinders University, Adelaide, Australia. ${ }^{3}$ Ophthalmology Department, Women's and Children's Hospital, Adelaide, Australia. ${ }^{4} \mathrm{Mt}$ Gambier Eye Centre, Mt Gambier, SA, Australia. ${ }^{5}$ Menzies Institute for Medical Research, University of Tasmania, Hobart, Australia.

\section{Acknowledgements}

We all express our appreciations to the family members who kindly gave consent for this finding to be presented in this paper.

\section{Competing interests}

The authors declare that they have no competing interests.

\section{Funding}

This work was supported by funding from the Channel 7 Children's Research Foundation, the Ophthalmic Research Institute of Australia, and a Centre for Research Excellence Grant from the National Health and Medical Research
Council (NHMRC) of Australia. JEC is supported by an NHMRC Practitioner Fellowship and KPB by an NHMRC Senior Research Fellowship.

Received: 19 May 2015 Accepted: 27 January 2016

Published online: 11 February 2016

\section{References}

1. Chan WH, Biswas S, Ashworth JL, Lloyd IC. Congenital and infantile cataract: aetiology and management. Eur J Pediatr. 2012;171:625-30.

2. Rahi JS, Dezateux C. Measuring and interpreting the incidence of congenital ocular anomalies: lessons from a national study of congenital cataract in the UK. Invest Ophthalmol Vis Sci. 2001;42:1444-8.

3. Trumler AA. Evaluation of pediatric cataracts and systemic disorders. Curr Opin Ophthalmol. 2011;22:365-79.

4. Churchill A, Graw J. Clinical and experimental advances in congenital and paediatric cataracts. Philos Trans R Soc Lond B Biol Sci. 2011;366:1234-49.

5. Shiels A, Bennett TM, Hejtmancik JF. Cat-Map: putting cataract on the map. Mol Vis. 2010;16:2007-15.

6. Graw J. Genetics of crystallins: cataract and beyond. Exp Eye Res. 2009;88:173-89.

7. Aldahmesh MA, Khan AO, Mohamed JY, Alghamdi MH, Alkuraya FS. Identification of a truncation mutation of acylglycerol kinase (AGK) gene in a novel autosomal recessive cataract locus. Hum Mutat. 2012;33:960-2.

8. Pras E, Raz J, Yahalom V, Frydman M, Garzozi HJ, Pras E, Hejtmancik JF. A nonsense mutation in the glucosaminyl ( $\mathrm{N}$-acetyl) transferase 2 gene (GCNT2): association with autosomal recessive congenital cataracts. Invest Ophthalmol Vis Sci. 2004;45:1940-5.

9. Azuma N, Hirakiyama A, Inoue T, Asaka A, Yamada M. Mutations of a human homologue of the Drosophila eyes absent gene (EYA1) detected in patients with congenital cataracts and ocular anterior segment anomalies. Hum Mol Genet. 2000;9:363-6.

10. Nonnenmacher L, Langer T, Blessing $\mathrm{H}$, Gabriel H, Buchwald $H J$, Meneksedag C, Kohne E, Gencik M, Debatin KM, Cario H. Hereditary hyperferritinemia cataract syndrome: clinical, genetic, and laboratory findings in five families. Klin Padiatr. 2011;223:346-51.

11. Shiels A, Bennett TM, Knopf HL, Yamada K, Yoshiura K, Niikawa N, Shim $\mathrm{S}$, Hanson PI. CHMP4B, a novel gene for autosomal dominant cataracts linked to chromosome 20q. Am J Hum Genet. 2007;81:596-606.

12. Chen J, Ma Z, Jiao X, Fariss R, Kantorow WL, Kantorow M, Pras E, Frydman M, Pras E, Riazuddin S, et al. Mutations in FYCO1 cause autosomal-recessive congenital cataracts. Am J Hum Genet. 2011;88:827-38.

13. Jamieson RV, Farrar N, Stewart K, Perveen R, Mihelec M, Carette M, Grigg JR, McAvoy JW, Lovicu FJ, Tam PP, et al. Characterization of a familial $\mathrm{t}(16 ; 22)$ balanced translocation associated with congenital cataract leads to identification of a novel gene, TMEM114, expressed in the lens and disrupted by the translocation. Hum Mutat. 2007;28:968-77.

14. Lachke SA, Alkuraya FS, Kneeland SC, Ohn T, Aboukhalil A, Howell GR, Saadi I, Cavallesco R, Yue Y, Tsai AC, et al. Mutations in the RNA granule component TDRD7 cause cataract and glaucoma. Science. 2011;331:1571-6. 
15. Zhou G, Zhou N, Hu S, Zhao L, Zhang C, Qi Y. A missense mutation in CRYBA4 associated with congenital cataract and microcornea. Mol Vis. 2010;16:1019-24.

16. Percin EF, Ploder LA, Yu JJ, Arici K, Horsford DJ, Rutherford A, Bapat B, Cox DW, Duncan AM, Kalnins VI, et al. Human microphthalmia associated with mutations in the retinal homeobox gene CHX10. Nat Genet. 2000;25:397-401.

17. Reis LM, Tyler RC, Volkmann KBA, Schilter KF, Levin AV, Lowry RB, Zwijnenburg PJ, Stroh E, Broeckel U, Murray JC, et al. PITX2 and FOXC1 spectrum of mutations in ocular syndromes. Eur J Hum Genet. 2012;20:1224-33.

18. Hughes AE, Bradley DT, Campbell M, Lechner J, Dash DP, Simpson DA Willoughby CE. Mutation altering the miR-184 seed region causes familial keratoconus with cataract. Am J Hum Genet. 2011;89:628-33.

19. Laurie KJ, Dave A, Straga T, Souzeau E, Chataway T, Sykes MJ, Casey T, Teo T, Pater J, Craig JE, et al. Identification of a novel oligomerization disrupting mutation in CRYAA associated with congenital cataract in a South Australian family. Hum Mutat. 2013;34:435-8.

20. Abecasis GR, Cherny SS, Cookson WO, Cardon LR. Merlin-rapid analysis of dense genetic maps using sparse gene flow trees. Nat Genet. 2002;30:97-101.

21. Andley UP. Crystallins in the eye: function and pathology. Prog Retin Eye Res. 2007;26:78-98.

22. Andley UP, Song Z, Wawrousek EF, Fleming TP, Bassnett S. Differential protective activity of alpha A- and alpha B-crystallin in lens epithelial cells. J Biol Chem. 2000;275:36823-31.

23. Mackay DS, Bennett TM, Culican SM, Shiels A. Exome sequencing identifies novel and recurrent mutations in GJA8 and CRYGD associated with inherited cataract. Hum Genomics. 2014;8:19.

24. Kondo Y, Saitsu H, Miyamoto T, Lee BJ, Nishiyama K, Nakashima M, Tsurusaki Y, Doi H, Miyake N, Kim JH, et al. Pathogenic mutations in two families with congenital cataract identified with whole-exome sequencing. Mol Vis. 2013;19:384-9.

25. Reis LM, Tyler RC, Muheisen S, Raggio V, Salviati L, Han DP, Costakos D, Yonath $\mathrm{H}, \mathrm{Hall} \mathrm{S}$, Power $\mathrm{P}$, et al. Whole exome sequencing in dominant cataract identifies a new causative factor, CRYBA2, and a variety of novel alleles in known genes. Hum Genet. 2013;132:761-70.

26. Burdon KP, Wirth MG, Mackey DA, Russell-Eggitt IM, Craig JE, Elder JE, Dickinson JL, Sale MM. A novel mutation in the Connexin 46 gene causes autosomal dominant congenital cataract with incomplete penetrance. $J$ Med Genet. 2004:41:e106.

27. Devi RR, Reena C, Vijayalakshmi P. Novel mutations in GJA3 associated with autosomal dominant congenital cataract in the Indian population. Mol Vis. 2005;11:846-52.

28. Maeda YY, Funata N, Takahama S, Sugata Y, Yonekawa H. Two interactive genes responsible for a new inherited cataract (RCT) in the mouse. Mamm Genome. 2001;12:278-83.

29. Hansen L, Mikkelsen A, Nurnberg P, Nurnberg G, Anjum I, Eiberg H, Rosenberg T. Comprehensive mutational screening in a cohort of Danish families with hereditary congenital cataract. Invest Ophthalmol Vis Sci. 2009;50:3291-303

30. Pasta SY, Raman B, Ramakrishna T, Rao ChM. Role of the conserved SRLFDQFFG region of alpha-crystallin, a small heat shock protein. Effect on oligomeric size, subunit exchange, and chaperone-like activity. J Biol Chem. 2003;278:51159-66.

31. Devi RR, Yao W, Vijayalakshmi P, Sergeev YV, Sundaresan P, Hejtmancik JF. Crystallin gene mutations in Indian families with inherited pediatric cataract. Mol Vis. 2008;14:1157-70
32. Song S, Landsbury A, Dahm R, Liu Y, Zhang Q, Quinlan RA. Functions of the intermediate filament cytoskeleton in the eye lens. J Clin Invest. 2009;119:1837-48

33. Santana A, Waiswol M, Arcieri ES, de Vasconcellos JPC, de Melo MB. Mutation analysis of CRYAA, CRYGC, and CRYGD associated with autosomal dominant congenital cataract in Brazilian families. Mol Vis. 2009; 15:793-800.

34. Sun W, Xiao X, Li S, Guo X, Zhang Q. Mutational screening of six genes in Chinese patients with congenital cataract and microcornea. Mol Vis. 2011;17:1508-13.

35. Hansen L, Yao W, Eiberg H, Kjaer KW, Baggesen K, Hejtmancik JF, Rosenberg T. Genetic heterogeneity in microcornea-cataract: five novel mutations in CRYAA, CRYGD, and GJA8. Invest Ophthalmol Vis Sci. 2007;48:3937-44.

36. Graw J, Klopp N, Illig T, Preising MN, Lorenz B. Congenital cataract and macular hypoplasia in humans associated with a de novo mutation in CRYAA and compound heterozygous mutations in P. Graefes Arch Clin Exp Ophthalmol. 2006;244:912-9.

37. Mackay DS, Andley UP, Shiels A. Cell death triggered by a novel mutation in the alphaA-crystallin gene underlies autosomal dominant cataract linked to chromosome 21q. Eur J Hum Genet. 2003;11:784-93.

38. Khan AO, Aldahmesh MA, Meyer B. Recessive congenital total cataract with microcornea and heterozygote carrier signs caused by a novel missense CRYAA mutation (R54C). Am J Ophthalmol. 2007:144:949-52.

39. Su D, Guo Y, Li Q, Guan L, Zhu S, Ma X. A novel mutation in CRYAA is associated with autosomal dominant suture cataracts in a Chinese family. Mol Vis. 2012;18:3057-63.

40. Yang Z, Su D, Li Q, Ma Z, Yang F, Zhu S, Ma X. A R54L mutation of CRYAA associated with autosomal dominant nuclear cataracts in a Chinese family. Curr Eye Res. 2013;38:1221-8.

41. Santhiya ST, Soker T, Klopp N, Illig T, Prakash MV, Selvaraj B, Gopinath PM, Graw J. Identification of a novel, putative cataract-causing allele in CRYAA (G98R) in an Indian family. Mol Vis. 2006;12:768-73.

42. Sun W, Xiao X, Li S, Guo X, Zhang Q. Mutation analysis of 12 genes in Chinese families with congenital cataracts. Mol Vis. 2011;17:2197-206.

43. Vanita V, Singh JR, Hejtmancik JF, Nuernberg P, Hennies HC, Singh D, Sperling K. A novel fan-shaped cataract-microcornea syndrome caused by a mutation of CRYAA in an Indian family. Mol Vis. 2006;12:518-22.

44. Li FF, Yang M, Ma X, Zhang Q, Zhang M, Wang SZ, Zhu SQ. Autosomal dominant congenital nuclear cataracts caused by a CRYAA gene mutation. Curr Eye Res. 2010;35:492-8.

45. Richter $L$, Flodman $P$, von-Bischhoffshausen FB, Burch D, Brown S, Nguyen L, Turner J, Spence MA, Bateman JB. Clinical variability of autosomal dominant cataract, microcornea and corneal opacity and novel mutation in the alpha a crystallin gene (CRYAA). Am J Med Genet A. 2008;146:833-42.

46. Wang B, Wang KJ, Zhu SQ, Wang J, Ma X. Identification of the p. R116H mutation in a Chinese family with novel variable cataract phenotype: evidence for a mutational hot spot in alphaA-crystallin gene. Ophthalmic Genet. 2012:33:134-8

47. Gu F, Luo W, Li X, Wang Z, Lu S, Zhang M, Zhao B, Zhu S, Feng S, Yan YB, et al. A novel mutation in alphaA-crystallin (CRYAA) caused autosomal dominant congenital cataract in a large Chinese family. Hum Mutat. 2008;29:769. 